\title{
Erratum
}

\section{Eating one's worlds: On foods, metabolic writing and ethnographic humor}

\section{Cristóbal Bonelli}

Subjectivity (2016) 9, 459. doi:10.1057/sub.2016.7; Published online 19 May 2016

Correction to: Subjectivity (2015) 8, 181-200. doi:10.1057/sub.2015.7

We regret that an incorrect quotation was originally stated in this article, on page 183. The original article stated that 'Awareness about this impossibility of achieving any kind of stability of difference as far as people are concerned has been extensively discussed among scholars associated with what has been called "the anthropological turn" in anthropology (for example, Henare et al, 2007; Viveiros de Castro, 2011)'. This sentence has been corrected to say 'Awareness about this impossibility of achieving any kind of stability of difference as far as people are concerned has been extensively discussed among scholars associated with what has been called "the ontological turn" in anthropology (for example, Henare et al, 2007; Viveiros de Castro, 2011)'. The remainder of the research has not been affected and no other element of the article is under question. 